\title{
A Safety Evaluation of Offshore Lattice Boom Crane
}

\author{
Heon-Jin Seong ${ }^{1}$, Chang-Kweon Jeong ${ }^{2}$, Jong-Hoon Jeon ${ }^{1}$, Sang-Hyeok Park ${ }^{1}$, Yong-Gil Jung ${ }^{1}$ and Sun-Chul Huh ${ }^{1, *}$ \\ ${ }^{1}$ Department of Mechanical and Energy Engineering, Gyeong-sang National University, Cheondaegukchi-Gil 38, Tong-Yeong, \\ Korea \\ ${ }^{2}$ DMC co., LTD, Gimhae-daero1102-171, Gimhae, Korea \\ ${ }^{*}$ Corresponding author
}

\begin{abstract}
Korea experienced a recession in the shipbuilding industry due to a decline in orders for vessels and a lack of orders from the Korean market. In 2017, the amount of orders has increased compared to the previous year, but it is expected to be only $60 \%$ of the previous level in 2020 . However, it will be 20 years from 2003, when shipbuilding orders have increased substantially in 2023. In this paper, the stress distribution and safety factor of Offshore Lattice Boom Crane mounted on offshore plant is confirmed in accordance with the luffing boom angle and critical load. The possibility of buckling is checked through buckling factor. In addition, OLBC was designed and evaluated based on API and ABS standards for offshore plants.
\end{abstract}

Keywords - lattice boom crane; offshore plant; CFX; buckling analysis; structural analysis

\section{INTRODUC TION}

In 2009, Korea experienced a recession in the shipbuilding industry due to a decline in orders for vessels and a lack of orders from the Korean market. In particular, the proportion of domestic orders is low compared to that of competitors, and the countermeasure has not been adequately addressed. In 2017, the amount of orders has increased compared to the previous year, but it is expected to be only $60 \%$ of the previous level in 2020 . However, it will be 20 years from 2003 , when shipbuilding orders have increased substantially in 2023, and it is time for shipbuilding orders ordered from 2003 to swell in earnest. Therefore, even if the replacement of old vessels is considered, the quantity of orders will increase in the future. As offshore plant orders increase, orders for offshore plant equipment will increase. In addition, shipbuilding specialization, enlargement, complexation.

In this study, the stress distribution and safety factor of OLBC (Offshore Lattice Boom Crane) mounted on floating offshore plant (FPSO) using ANSYS analysis program is confirmed in accordance with the luffing boom angle and critical load. The possibility of buckling is checked through buckling factor. In addition, OLBC was designed and evaluated based on API and ABS standards for offshore plants. supporting the entire structure, and a deck connecting three structures.

The boom parts were designed with S355J2 yield strength of $355 \mathrm{MPa}$ and deck and pedestal part with DH36 of $350 \mathrm{MPa}$ considering corrosion and safety when used at sea condition.

Since the actual model of OLBC is a complicated form to perform the finite element analysis, the model is simplified by using CATIA. In addition, the model is divided into 10 parts in order to generate a dense and delicate mesh, and collision inspection is carried out to be recognized as one structure. 3D modeling of LBC is shown in Figure $1[1,2]$.

The line body in the ANSYS the design Modeler was used to give consideration to the luffing wire supporting the whole boom parts [3-5].

The FPSO on which the OLBC is mounted is a floating type with drilling energy resources as well as producing, storing and transporting. The stability of the structure was evaluated during on board in order to take into consideration the continuously changing environmental loads. Therefore, the working environment of OLBC is divided into on board and off board. The luffing angle is divided into $28^{\circ}, 61^{\circ}$ and maximum $80^{\circ}$, and the structure is analyzed under 6 conditions. The CFX analysis was carried out to consider the wind loads under all conditions $[6,7]$.

The pipes, which is the main structure of the OLBC, have a length longer than the cross-sectional area, and when the compressive load reaches the axial direction, the buckling phenomenon may occur in which the pipe is excessively bent in the transverse direction suddenly. Based on the pipe thickness, we divided the boom part, the gantry part and the pedestal part to judge the possibility of buckling. Table 1 summarizes the structural analysis conditions and procedures $[8,9]$.

\section{OFFSHORE LATTICE BOOM CRANE STRUCTURE}

\section{A. Structual Analysis Procedure and 3D Modeling}

The OLBC has a height $33 \mathrm{~m}$, a maximum working radius $42 \mathrm{~m}$, a boom and a gantry for luffing and hoisting, a pedestal 


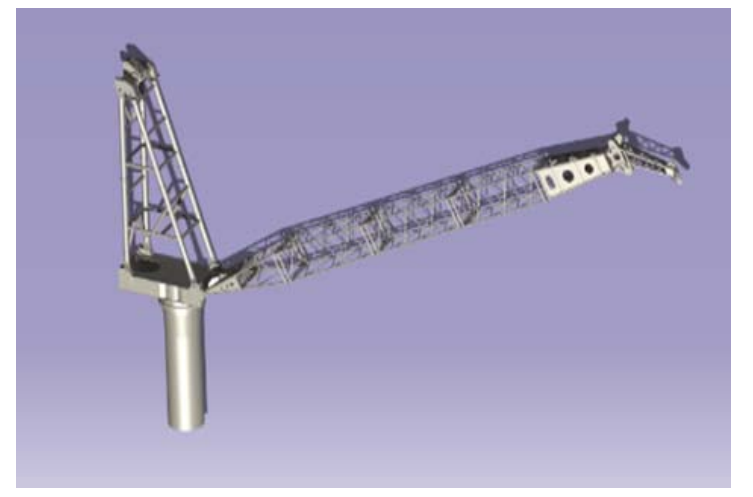

FIGURE I. 3D MODELING OF OLBC BY CATIA

TABLE I. THE ANALYSIS CONDITIONS

\begin{tabular}{|c|c|c|c|c|c|c|}
\hline \multirow{2}{*}{ Case } & \multicolumn{7}{|c|}{ Table Column Head } \\
\cline { 2 - 7 } & $\mathbf{1}$ & $\mathbf{2}$ & $\mathbf{3}$ & $\mathbf{4}$ & $\mathbf{5}$ & $\mathbf{6}$ \\
\hline${\text { Luffing angle }\left[{ }^{\circ}\right]}$ & 28 & 61 & 80 & 28 & 61 & 80 \\
\hline Load[Ton] & 10 & 24 & 60 & 6 & 15 & 40 \\
\hline CFX analysis & $\mathrm{O}$ & $\mathrm{O}$ & $\mathrm{O}$ & $\mathrm{O}$ & $\mathrm{O}$ & $\mathrm{O}$ \\
\hline Static Analysis & $\mathrm{O}$ & $\mathrm{O}$ & $\mathrm{O}$ & $\mathrm{O}$ & $\mathrm{O}$ & $\mathrm{O}$ \\
\hline $\begin{array}{c}\text { Buckling } \\
\text { Analysis }\end{array}$ & $\mathrm{O}$ & & $\mathrm{O}$ & & & $\mathrm{O}$ \\
\hline
\end{tabular}

\section{B. Environmental Loads}

\section{1) Acceleration}

Floating offshore plants are required to adhere to a fixed position for a long time in a rough sea environment, and it is very important from a design point of view to accurately predict and interpret environmental loads caused by waves, winds. The irregular motion caused by the wind and the continuous motion by the waves also affects the OLBC mounted on the floating offshore plant. In order to apply this wave motion as an environmental condition, the significant wave height $\left(\mathrm{H}_{\text {sig }}\right)$ was selected as $2 \mathrm{~m}$ and the acceleration was calculated in the 3-axis direction based on the offshore classification regulations. The accelerations calculated from (1) and (2) are $687.02 \mathrm{~mm} / \mathrm{s}^{2}$ in the vertical direction $\left(A_{V}\right)$ and $785.16 \mathrm{~mm} / \mathrm{s}^{2}$ in the horizontal direction $\left(\mathrm{A}_{\mathrm{H}}\right)$, respectively [10].

$$
\begin{gathered}
A_{R S}=0.01 \times\left(H_{\text {sig }}\right)^{1-1} \geq 0.03 \\
A_{V^{5}}=0.0012 \times H_{\text {sig }} \times H_{\text {sig }} \geq 0.07
\end{gathered}
$$

\section{2) Dynamic factor}

The offshore structure is exposed to various environmental loads, but small loads with a fine and complex effect cannot be simulated. Therefore, according to the API classification rules, the dynamic factors are obtained by dividing into two environments, on and off shore. Each dynamic factors are applied to hoisting loads to evaluate safety. The dynamic factor
$\left(\mathrm{C}_{\mathrm{V}}\right)$ of 1.42 on board and 2.00 off shore are obtained through (3) $[11]$.

$$
C_{p}= \begin{cases}1+p_{r} \times \sqrt{\frac{K}{g \times S W L L}}\left(O_{n} \text { Baard }\right) \\ 1.37-\frac{S W L L F}{1173913}+A_{p} & (\text { Off Baard })\end{cases}
$$

\section{3) Pedestal factor}

The pedestal substructure supporting the booms, gantry and deck should be designed for loads with pedestal factor applied to the vertical load. The pedestal factor is applied according to the three luffing angle conditions because the weight of the OLBC and the vertical load applied to the end of the boom generate a large moment affected the bottom of pedestal. The P.F. of 1.5 at 28 and 61 degrees, and 1.41 at 80 degrees are calculated through (4).

$$
\text { P.F. }=1.56-\frac{S W L H}{900000}
$$

\section{The NumericAl Finite ElEMENT ANALysis}

\section{A. CFX Analysis}

Since off shore plant cranes are located at sea, unlike land crane, wind load should be considered for the safety evaluation. OLBC is a complicated structure with thin-walled pipes intersecting each other, so it is difficult to calculate the pressure of the area subjected to direct wind load. Also, to realize geometry modeling and mesh generation, the boom parts of the structure was modeled as a single hexahedron. Simplified components do not seem to have a big impact on the overall wind load of the crane. In order to derive the flow pressure due to wind speed, flow field was created at $165 \mathrm{~m}$ in the opposite direction of the wind velocity and $82.5 \mathrm{~m}$ at the rest, and the flow was applied to the inlet with the wind velocity of $20 \mathrm{~m} / \mathrm{s}$.

The configuration of the mesh is very important to obtain accurate results in the CFX analysis. However, when the entire flow field is composed of dense meshes, the analysis time increases exponentially. In order to obtain fast and accurate pressure results, the crane surface was formed as a dense mesh, and as it moved away from the crane surface, it was formed as a large mesh.

\section{B. The Results of CFX Analysis Units}

Table 2 shows the results of the CFX analysis of luffing angles. Turbulence occurred at the rear of the crane that was blown by the stream line, and maximum pressure was generated at the boom part and pedestal directly in front of the wind. It can be seen that the maximum pressure is not concentrated on one part and the wind load acts on the surface as a whole. The average luffing angle was $258 \mathrm{~Pa}$ with $\pm 5 \mathrm{~Pa}$ difference under three conditions. 
As a result of the overall flow analysis, it is necessary to consider the wind load as a structure to be used in the sea. However, OLBC has a relatively small wind receiving area, the wind is properly distributed between the pipes and the pressure of wind is small. Simplified flow CFX results can be interpreted as an overestimation, but the maximum pressure, $\mathrm{Pa}$, is negligible compared to a $40 \mathrm{~m}$ high crane. This result shows that when the boom part is modeled as a single large hexahedron, the maximum area of the truss is reduced and the maximum pressure is further reduced.

\section{Static Structual Analysis}

Static structural analysis is performed by applying the maximum pressure obtained from the CFX analysis and the load derived from the load equation as the boundary conditions.

In order to consider the crane self weight, gravity was applied as standard earth gravity, and the acceleration due to the wave and the pressure are given as boundary conditions [12].

TABLE II. THE RESULTS OF CFX ANALYSIS

\begin{tabular}{|l|l|l|l|}
\hline \multicolumn{2}{|c|}{ Conditions } & \multicolumn{1}{|c|}{ Luffing angle } & Maximum pressure \\
\hline \multirow{3}{*}{ Case } & 1 & $28^{\circ}$ & $261 \mathrm{~Pa}$ \\
\cline { 2 - 2 } & 4 & & \\
\cline { 2 - 2 } & 2 & $61^{\circ}$ & $258 \mathrm{~Pa}$ \\
\cline { 2 - 2 } & 5 & & \\
\cline { 2 - 3 } & 3 & $80^{\circ}$ & $256 \mathrm{~Pa}$ \\
\cline { 2 - 3 } & 6 & & \\
\hline
\end{tabular}

1) The hoisting load

The OLBC is a crane that lifts the cargo using a wire rope. The cargo should be fixed by applying a hoisting load considering the luffing angle and the safety load. In order to apply hoisting load as a boundary condition, it is applied in X direction and $\mathrm{Y}$ direction, respectively, and it is shown in Table 3 .

\section{2) The lifting load}

Table 3 summarizes the lifting loads applied to the cranes under the six conditions of analysis in terms of the acceleration of the offshore plant in three axial directions (1) and (2), the dynamic factor (3) and the pedestal factor (4). The loads in Table 3 are applied to the boundary conditions according to the analysis conditions.

TABLE III. THE RESULTS OF STATIC ANALYSIS

\begin{tabular}{|c|l|l|l|l|l|l|}
\hline & \multicolumn{3}{|c|}{ On Board } & \multicolumn{3}{c|}{ Off Board } \\
\hline & Case1 & Case2 & Case3 & Case4 & Case5 & Case6 \\
\hline \multirow{2}{*}{$\begin{array}{c}\text { Lifting } \\
\text { load[N] }\end{array}$} & 16268 & 35280 & 83711 & 19237 & 39935 & 98088 \\
\cline { 2 - 7 } & 14023 & 30321 & 71824 & 12789 & 31928 & 78027 \\
\cline { 2 - 7 } & 162062 & 245775 & 857862 & 149871 & 326271 & 816271 \\
\hline \multirow{2}{*}{$\begin{array}{c}\text { Hoisting } \\
\text { load[N] }\end{array}$} & 42189 & 62112 & 72598 & 39023 & 55428 & 70040 \\
\cline { 2 - 7 } & 14278 & 78929 & 220784 & 13210 & 80553 & 213032 \\
\hline
\end{tabular}

\section{The Results of Static Structure}

Table 4 shows the maximum stress and the safety factor as the static analysis results of $28^{\circ}, 61^{\circ}$ and $80^{\circ}$ at the land and sea, and the static analysis results are summarized by the roughing angle.
TABLE IV. THE MAX STRESS AND SAFETY FACTOR OF STATIC ANALYSIS

\begin{tabular}{|c|l|l|l|l|l|l|}
\hline & \multicolumn{3}{|c|}{ On Board } & \multicolumn{3}{c|}{ Off board } \\
\hline $\begin{array}{c}\text { Maximum } \\
\text { stress }\end{array}$ & Case1 & Case2 & Case3 & Case4 & Case5 & Case6 \\
\hline $\begin{array}{c}\text { Safety } \\
\text { factor }\end{array}$ & 195.16 & 151.29 & 242.3 & 186.06 & 142.42 & 254.59 \\
\cline { 2 - 7 } & 1.82 & 2.35 & 1.47 & 1.91 & 2.49 & 1.39 \\
\hline
\end{tabular}

1) The static structural analysis results of Case1 and 4

Case 1 and 4 are static structural analysis results of 10 ton and 6 ton at a luffing angle of $28^{\circ}$. The maximum stresses were 195.16 $\mathrm{MPa}$ and $186.06 \mathrm{MPa}$ in the back pipe of the gantry. The hoisting load occurred in the $-\mathrm{x}$ and $-\mathrm{y}$ directions while the maximum stress occurred in the gantry (boom part direction) connected to the boom and the line body. An average of 90 $\mathrm{MPa}$ of stress was produced in the boom part and $158.3 \mathrm{MPa}$ in the fifth boom part connected to the line body. For pedestals and decks, stresses of less than $160 \mathrm{MPa}$ can be observed.

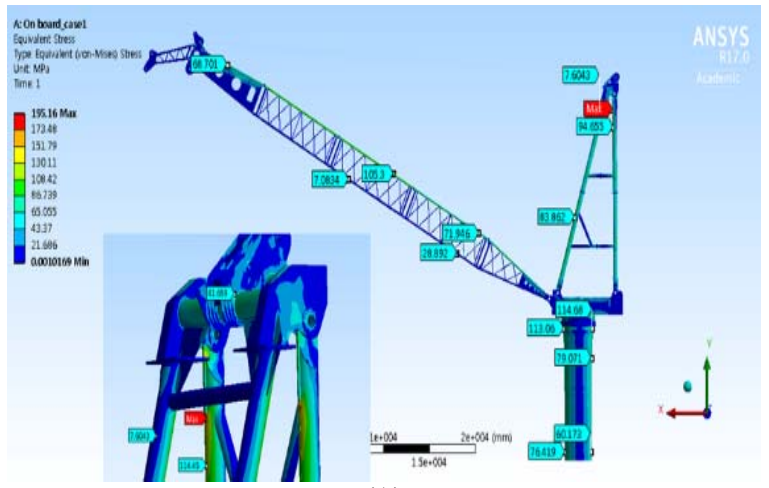

(A)

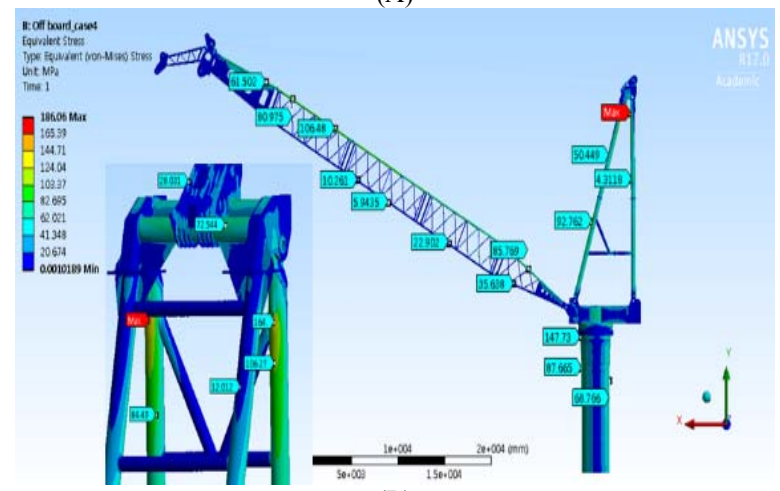

(B)

FIGURE II. THE STATIC ANALYSIS RESULTS OF $28^{\circ}$ : (A) THE STATIC ANALYSIS RESULTS OF CASE1; (B) THE STATIC ANALYSIS RESULTS OF CASE4.

2) The static structural analysis results of Case 2 and 5

Case 2 and 5 are static structural analysis results of 24 ton and 15 ton at a luffing angle of $61^{\circ}$. In Case 2, the maximum stress was 151.29 MPa at the deck and pedestal connection, and the maximum stress at Case 5 was $142.42 \mathrm{MPa}$ at the downward position of Case2.

The maximum stress in the deck and pedestal occurred as the boom was struck in the gravity direction, while the lifting load was greater in the -y direction. The average stress at the top of the boom was $70 \mathrm{MPa}$ and the average stress at the 
bottom of the boom was $50 \mathrm{MPa}$, which was smaller than the deck and pedestal gantry parts.

The vicinity of the luffing angle of $45^{\circ}$ is used in the actual field and is not widely used at the minimum and maximum luffing angles due to boom deflection and possibility of buckling. At a luffing angle of $61^{\circ}$, the average stress of the boom is $60 \mathrm{MPa}$, and the safety factor of the whole structure is the highest at 2.35 and 2.49 in the 6 cases.

3) The static structural analysis results of Case 3 and 6

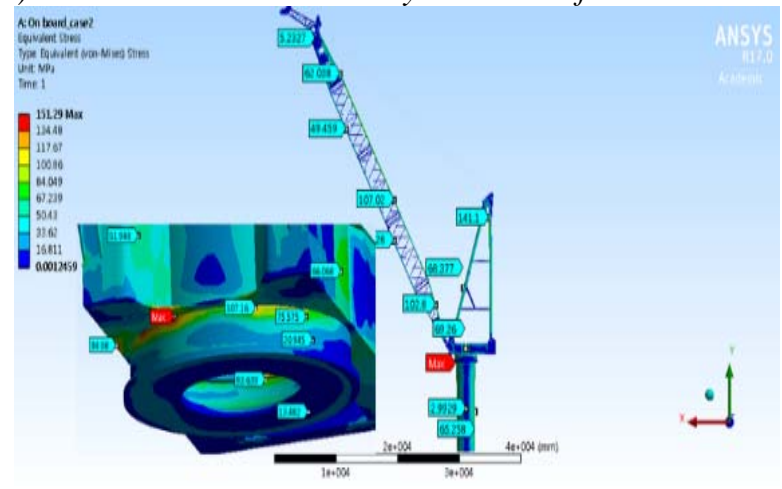

(A)

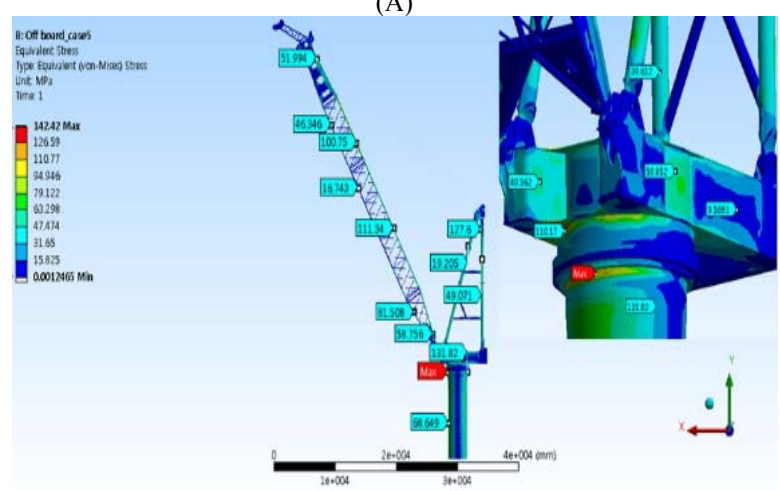

(B)

FIGURE III. THE STATIC ANALYSIS RESULTS OF $61^{\circ}$ : (A) THE STATIC ANALYSIS RESULTS OF CASE2; (B) THE STATIC ANALYSIS RESULTS OF CASE5

Case 3, 6 are static structural analysis results of 60 ton and 40 ton at a luffing angle of $80^{\circ}$. The maximum stresses in the pipe under the second boom were $242.3 \mathrm{MPa}$ and $254.59 \mathrm{MPa}$, respectively. Unlike the results of the previous analysis, larger stresses occurred in the marine environment than on land.

In the second boom part where the maximum stress occurred, the stress difference was larger than the difference between the pedestal, deck and gantry in each part, but the overall stress distribution was larger than the four structural analysis results. In addition, unlike the results of large stress distribution above the lower part of the boom in the results of Case 1, 2, 4 and 5, the stress at the lower part of the boom is two to three times higher than the upper part of the boom. This is because the y-direction load of the lifting has a great influence on the vertical direction of the pipe section, and the buckling phenomenon is likely to occur. However, all of the maximum stresses occurred at a lower load than the yield strength used.

\section{BUCKLING ANALYSIS}

The buckling analysis was performed in Case 6 where the maximum stress occurred in the boom to determine the safety of the structure. In case 1 and case 3, where the maximum stress occurred in the gantry and pedestal part, which consist of a small section area and a long length, buckling analysis was performed to determine the linear buckling stability [13, 14].

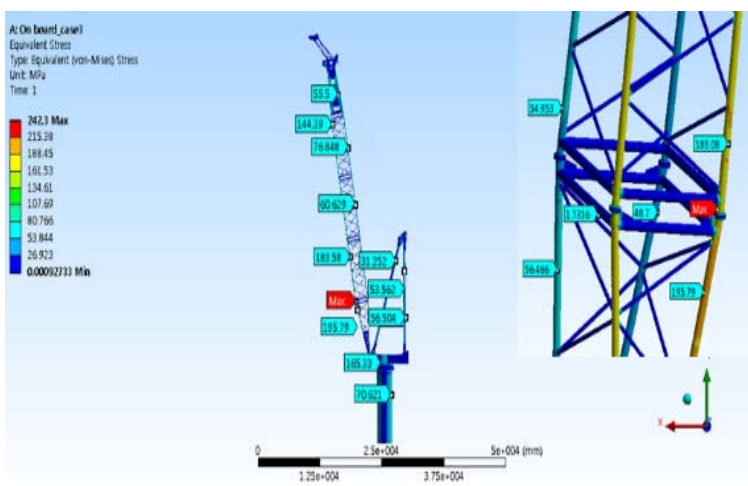

(A)

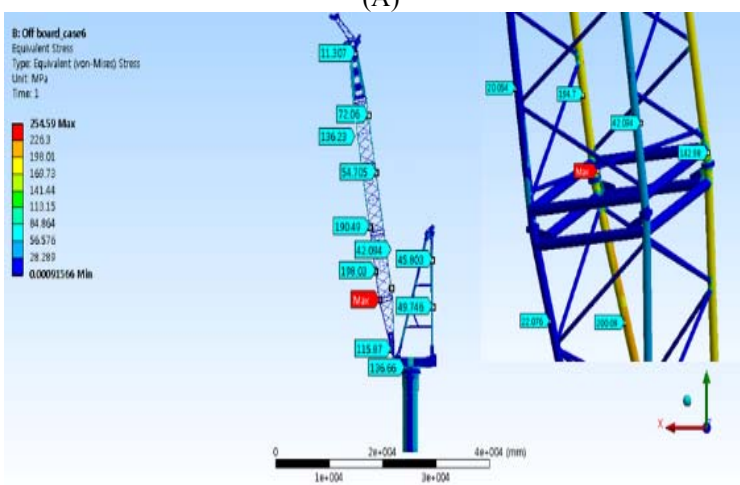

(B)

FIGURE IV. THE STATIC ANALYSIS RESULTS OF $80^{\circ}$ : (A) THE STATIC ANALYSIS RESULTS OF CASE3; (B) THE STATIC ANALYSIS RESULTS OF CASE6

\section{1) Boundary conditions}

In Figure 5 (a), the pin connected to the deck is fixed, gravity is applied to apply self weight, and the luffing load is applied as boundary condition in Case1.

In Figure 5 (b), in case 3, the pedestal underside is fixed and the force of the entire crane structure is applied as boundary conditions. In case of pedestal, its own weight is not considered because it is not greatly influenced by external environmental load.

In Figure 5 (c), in Case 6, the hoisting and lifting loads of the static structural analysis are applied and gravity is applied as a self weight. 


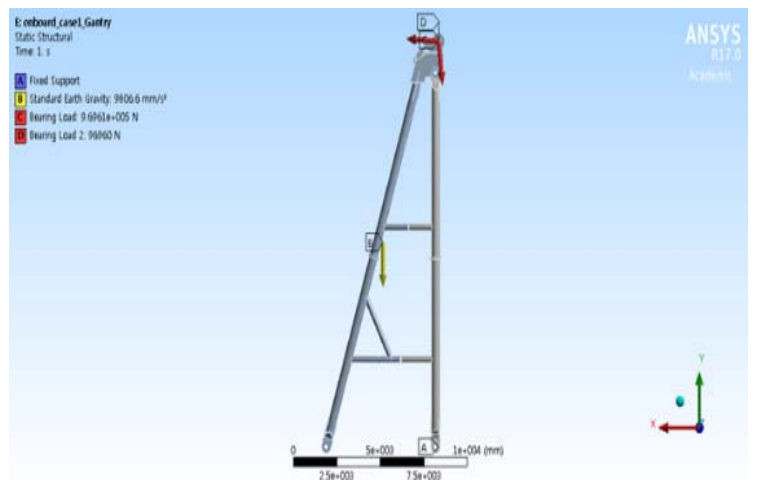

(A)

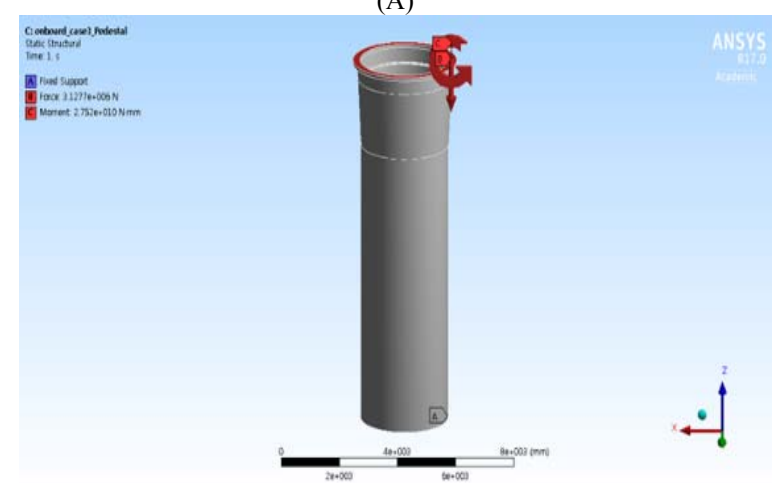

(B)

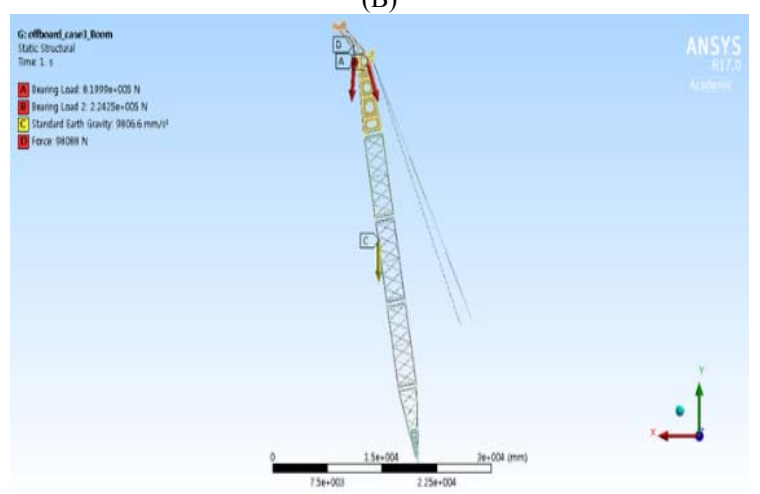

(C)

FIGURE V. BOUNDARY CONDITIONS OF BUCKLING ANALYSIS : (A) BOUNDARY CONDITION OF CASE1; (B) BOUNDARY CONDITION OF CASE3; (C) BOUNDARY CONDITION OF CASE6

\section{2) The buckling results}

Table 5 shows the buckling analysis results. In Case 1, the buckling analysis of the gantry shows that the critical load factor is 12.58 , the pedestal critical load factor is 22.93 in Case 3 , and the critical load factor of the boom is 5.41 in Case 6 where the greatest stress occurs. In all three conditions, the critical load factor is over than 1 , which means the linear stability of the structure.

TABLE V. THE RESULTS OF BUCKLING ANALYSIS

\begin{tabular}{|l|l|l|}
\hline \multicolumn{1}{|c|}{ Conditions } & \multicolumn{1}{|c|}{ Part } & \multicolumn{1}{c|}{ Buckling load factor } \\
\hline Case 1 & Gantry & 12.58 \\
\hline Case 3 & Pedestal & 22.93 \\
\hline Case6 & Boom & 5.41 \\
\hline
\end{tabular}

\section{CONCLUSIONS}

This study evaluated the safety of OLBC for offshore plant through finite element analysis. In order to consider the complex external environment loads, the CFX analysis results were applied as the boundary condition of the static structural and buckling analysis in six conditions.

1. As a result of CFX analysis, it was carried out under three conditions according to luffing angle, and it was found that the average was $258 \mathrm{~Pa}$ and distributed evenly over the maximum area of the crane. .

2. Structural analysis was carried out under 6 conditions according to use environment and luffing angle. As a result of the structural analysis, the maximum stress lower than the yield strength occurred and satisfied the safety factor of 1.2. In addition, the maximum stress was found to be the smallest and safe result at the most used angle in actual unloading.

3. Linear buckling analysis was performed by dividing the long pipe structure, which is likely to buckle, into parts. As a result of the buckling analysis of the boom with the greatest stress, it was confirmed that the buckling did not occur with the critical load factor of 1.41 or more.

\section{ACKNOWLEDGMENT}

This study is the result of research carried out under the support of the project for the promotion of the economic cooperation industry (R0004464).

\section{REFERENCES}

[1] Schaub, H. Rate-based ship-mounted crane payload pendulation control system. Control Engineering Practice 2008, 16, 132-145.

[2] He, B.; Tang, W.; Cao, J. Virtual prototyping-based multibody systems dynamics analysis of offshore crane. The International Journal of Advanced Manufacturing Technology 2014, 75, 161-180.

[3] Li, W.; Zhao, J.; Jiang, Z.; Chen, W.; Zhou, Q. A numerical study of the overall stability of flexible giant crane booms. Journal of Constructional Steel Research 2015, 105, 12-27.

[4] Wang, G.; Qi, Z.; Kong, X. Geometrical nonlinear and stability analysis for slender frame structures of crawler cranes. Engineering Structures 2015, 83, 209-222.

[5] Ham, S.; Roh, M.; Lee, H.; Ha, S. Multibody dynamic analysis of a heavy load suspended by a floating crane with constraint-based wire rope. Ocean Engineering 2015, 109, 145-160.

[6] Chu, Y.; AEsoy, V.; Zhang, H.; Bunes, O. Modelling and Simulation of an Offshore Hydraulic Crane. $28^{\text {th }}$ European Conference on Modeling and Simulation. 2014.

[7] Messineo, S., Serrani, A. Offshore crane control based on adaptive external models. Automatica 2009, 45, 2546-2556.

[8] Chu, Y.; Sanfilippo, F.; Asoy, V.; Zhang, H. An effective heave compensation and anti-sway control approach for offshore hydraulic crane operations. In 2014 IEEE International Conference on Mechatronics and Automation 2014.

[9] Kong, X.; Qi, Z.; Wang, G. Elastic instability analysis for slender latticeboom structures of crawler cranes. JCSR 2015, 115, 206-222.

[10] Küchler, S.; Mahl, T.; Neupert, J.; Schneider, K.; Sawodny, O. Active control for an offshore crane using prediction of the vessels motion. IEEE/ASME Transactions on Mechatronics 2011, 16, 297-309.

[11] Maczynski, A.; Wojciech, S. Dynamics of a mobile crane and optimisation of the slewing motion of its upper structure. Nonlinear Dynamics 2003, 32, 259-290. 
[12] He, Y.; Zhou, X.; Zhang, X. Finite element analysis of the elastic static properties and stability of pretensioned cylindrical reticulated megastructures. Thin-Walled Structures 2012, 60, 1-11.

[13] Turvey, G. J.; Zhang, Y. A computational and experimental analysis of the buckling, postbuckling and initial failure of pultruded GRP columns. Computers and Structures 2006, 84, 1527-1537.

[14] Jankowska-Sandberg, J.; Kołodziej, J. Experimental study of steel truss lateral-torsional buckling. Engineering Structures 2013, 46, 165-172. 